\title{
Screening and surgery for foramen magnum stenosis in children with achondroplasia: a large, national database analysis
}

\author{
Jeffrey L. Nadel, MS, ${ }^{1}$ D. Andrew Wilkinson, MD, ${ }^{2}$ Hugh J. L. Garton, MD, MSc, ${ }^{2}$ \\ Karin M. Muraszko, MD, ${ }^{2}$ and Cormac O. Maher, MD² \\ ${ }^{1}$ School of Medicine and ${ }^{2}$ Department of Neurosurgery, University of Michigan, Ann Arbor, Michigan
}

OBJECTIVE The goal of this study was to determine the rates of screening and surgery for foramen magnum stenosis in children with achondroplasia in a large, privately insured healthcare network.

METHODS Rates of screening and surgery for foramen magnum stenosis in children with achondroplasia were determined using de-identified insurance claims data from a large, privately insured healthcare network of over 58 million beneficiaries across the United States between 2001 and 2014. Cases of achondroplasia and screening and surgery claims were identified using a combination of International Classification of Diseases diagnosis codes and Current Procedural Terminology codes. American Academy of Pediatrics (AAP) practice guidelines were used to determine screening trends.

RESULTS The search yielded 3577 children age 19 years or younger with achondroplasia. Of them, 236 met criteria for inclusion in the screening analysis. Among the screening cohort, $41.9 \%$ received some form of screening for foramen magnum stenosis, whereas $13.9 \%$ of patients were fully and appropriately screened according to the 2005 guidelines from the AAP. The screening rate significantly increased after the issuance of the AAP guidelines. Among all children in the cohort, 25 underwent cervicomedullary decompression for foramen magnum stenosis. The incidence rate of undergoing cervicomedullary decompression was highest in infancy (28 per 1000 patient-years) and decreased with age (5 per 1000 patient-years for all other ages combined).

CONCLUSIONS Children with achondroplasia continue to be underscreened for foramen magnum stenosis, although screening rates have improved since the release of the 2005 AAP surveillance guidelines. The incidence of surgery was highest in infants and decreased with age.

https://thejns.org/doi/abs/10.3171/2018.9.PEDS18410

KEYWORDS achondroplasia; screening; foramen magnum stenosis; cervicomedullary decompression; pediatrics; congenital

A CHONDROPLASIA is the most common form of infantile skeletal dysplasia, with a reported prevalence rate ranging from 0.36 to 1.5 per 10,000 individuals. ${ }^{17,29}$ Neurological sequelae may present in as many as $47 \%$ of patients with achondroplasia ${ }^{22}$ as a result of congenital spinal stenosis, foramen magnum stenosis, and macrocrania with or without hydrocephalus. ${ }^{5,6,8,9,13,22,31}$ Among these abnormalities, foramen magnum and high cervical spinal stenosis are the most concerning, given that the resultant brainstem compression has been implicated in central sleep apnea and sudden infant death.,10,18,19,26,30
To this point, numerous single-center case reports and case series have described the role and safety profile of cervicomedullary decompression for foramen magnum stenosis in children with achondroplasia. , $^{2,111,14,16,23-25,32,33}$ It is now widely considered the standard of care for children exhibiting signs and symptoms of foramen magnum compression. ${ }^{28}$ However, given the infrequency with which any one center performs this procedure, it has been difficult to ascertain how many children with achondroplasia will eventually require cervicomedullary decompression and at what time in life. Understanding the natural history of

ABBREVIATIONS AAP = American Academy of Pediatrics; $\mathrm{CPT}=$ Current Procedural Terminology .

SUBMITTED July 3, 2018. ACCEPTED September 26, 2018.

INCLUDE WHEN CITING Published online December 14, 2018; DOI: 10.3171/2018.9.PEDS18410. 
achondroplastic foramen magnum stenosis and the timing of interventions has implications for screening recommendations in these children.

In 1995, the American Academy of Pediatrics (AAP) released their first recommendations for overall health surveillance of children with achondroplasia. ${ }^{1}$ The recommendations did not include routine neuroimaging for achondroplasia due to the perceived rarity of serious and fatal events in infancy. However, in 2005, the recommendations were revised to recommend that all infants with achondroplasia undergo neuroimaging with CT or MRI as well as polysomnography. ${ }^{27}$ In the absence of highlevel evidence, the authors of the recommendation cited advancements in neuroimaging technology, improved risk assessment, and a better appreciation of the number of children with critical stenosis as the rationale for the change. ${ }^{4,12,14,18-21}$ Importantly, the guidelines do not offer indications for surgical intervention for foramen magnum stenosis. Instead, they suggest that severe abnormalities in an infant's neurological examination (e.g., profound hypotonia or sustained ankle clonus), markedly diminished foramen magnum size compared with average children with achondroplasia, or hypoxemic episodes with oxygen saturations less than $85 \%$ should prompt a referral for neurosurgical evaluation. Since the 2005 guidelines revision, there has been no assessment of adherence to screening recommendations.

Now, access to large, nationally representative databases has enabled the investigation of screening adherence and surgical trends. The purpose of this study was to 1) evaluate adherence to recommended screening guidelines and 2) describe the incidence rate of cervicomedullary decompression in children with achondroplasia using a large, nationally representative sample.

\section{Methods}

Clinformatics Data Mart (Optum) database contains de-identified insurance claims from a large, private healthcare network of over 58 million enrollees in the US between 2001 and 2014. Using both International Classification of Diseases diagnosis codes and Current Procedural Terminology (CPT) codes, we identified all enrollees with achondroplasia and their associated medical and surgical procedures throughout their period of longest insurance coverage.

Start and end dates of all enrollment periods were available for each patient, and we analyzed the longest period of continuous enrollment not interrupted by more than a 30-day gap. Socioeconomic and demographic variables were available for each patient, including sex, race, household income, and household net worth. Because the data were de-identified, the University of Michigan institutional review board considered this to be a nonregulated study.

\section{Identification of Base Cohort of Pediatric Patients With Achondroplasia}

Figure 1 and Appendix Fig. 1 outline the details of the identification strategy for the screening and surgical incidence rate analyses, respectively. The database was queried for all enrollees with a medical claim containing the ICD-9-CM diagnosis code of 756.4 (chondrodystrophy, achondroplasia) between January 1, 2001, and December 31,2014. A list of unique enrollees was generated, and all other outpatient medical and inpatient claims for these individuals were extracted from the database. Given limitations within the data set, not all enrollees had data for each of the socioeconomic and demographic variables listed above. Enrollees missing all socioeconomic and demographic information were excluded from the analysis. Enrollees were considered pediatric if they were $\leq 19$ years old at the time of their insurance enrollment. Any enrollee 20 years or older was excluded from the analysis. For HIPAA compliance, the data only include information on year of birth, rather than full date of birth, and consequently, date of birth was assumed to be July 1 at the midpoint of the year for purposes of calculating time to surgery.

\section{Identification of Screening Cohort}

In order to examine adherence to the recommended screening guidelines-some form of neuroimaging and a sleep study by approximately 1 year of life-enrollees were excluded if they were not age 0 years at the time of enrollment and did not have at least 18 months of continuous coverage. Age of enrollment was calculated by subtracting the enrollee's year of birth from the year that the enrollee enrolled in coverage. Length of coverage in days was provided in the data set.

\section{Screening Analysis}

An enrollee was said to have undergone screening with neuroimaging if the enrollee's medical claims file included a CPT code for one or more of the following imaging studies: CT scanning of the brain with or without contrast (70460, 70450, or 70470); CT scanning of the cervical spine with or without contrast $(72126,72125$, or 72127); MRI of the brain with or without contrast (70552, 70551, 70553); or MRI of the cervical spine with or without contrast $(72142,72141,72156)$. Polysomnography was identified using 1 or more of the following CPT codes for in-office or home-based sleep studies: 95806, 95800, 95801, 95807, 95808, 95810, 95811, 95782, 95783. Patients in the screening cohort were also stratified by birth year into those in the first half of the study (2001-2007) versus those in the latter half (2008-2014).

\section{Identification of Cervicomedullary Decompression Procedures}

We defined cervicomedullary decompression as CPT code 61343 (craniectomy, suboccipital with cervical laminectomy for decompression of medulla and spinal cord, with or without dural graft) or CPT code 61345 (other cranial decompression, posterior fossa).

\section{Calculation of Surgical Incidence Rates}

All enrollees from the base cohort were stratified into 5 age brackets based on their age at entry into the data set: ages $0-3,4-7,8-11,12-15$, and $16-19$ years. The total number of enrollees and their total coverage years were recorded. The enrollees who had cervicomedullary 


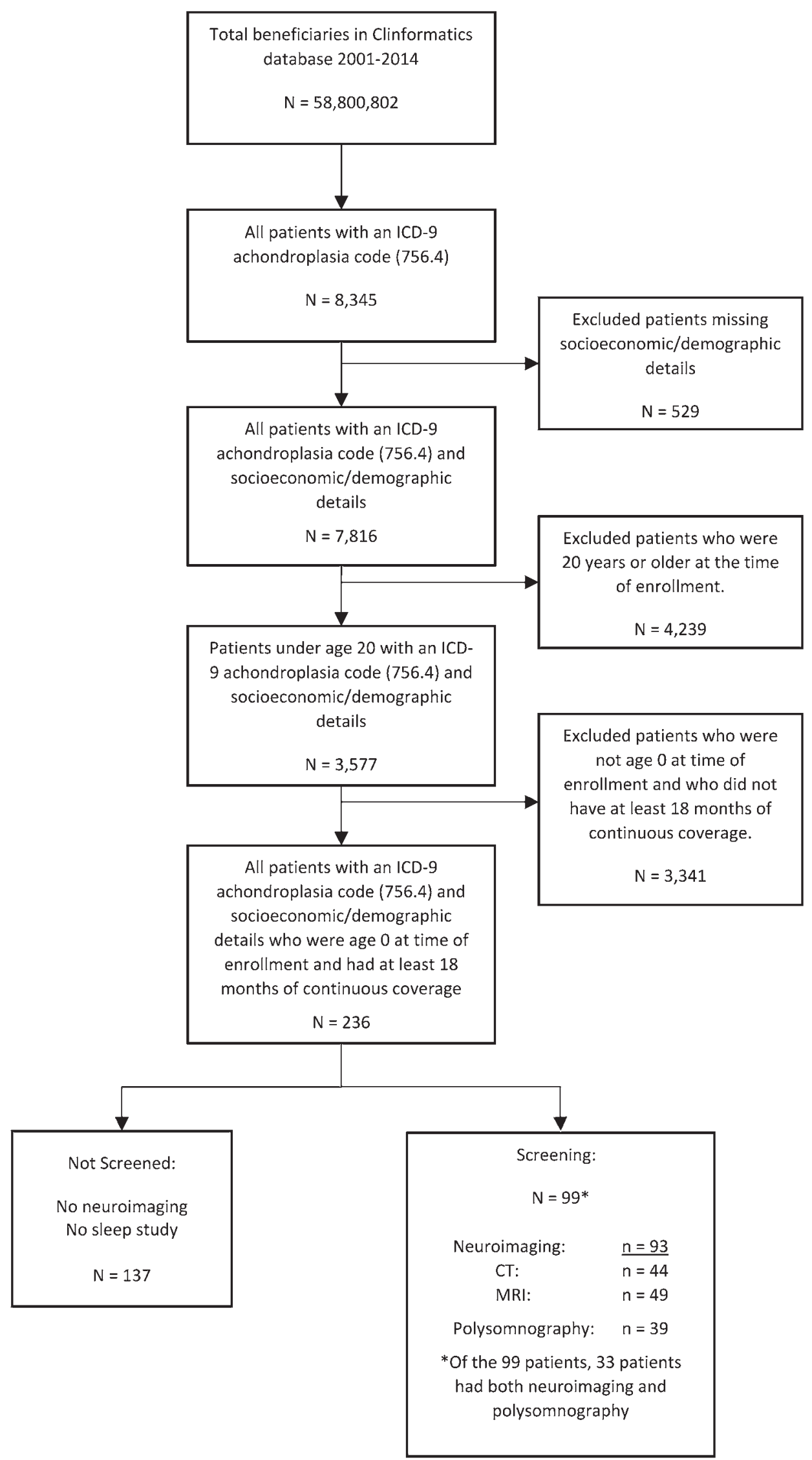

FIG. 1. Patient identification algorithm for achondroplasia screening. 
TABLE 1. Demographic characteristics of beneficiaries in the overall cohort

\begin{tabular}{ccccccr}
\hline & \multicolumn{5}{c}{ No. of Patients $(\%)$} \\
\cline { 2 - 7 } Variable & Total & Age 0-3 & Age 4-7 & Age 8-11 & Age 12-15 & Age 16-19 \\
\hline Sex & 3577 & 733 & 567 & 870 & 956 & 451 \\
\hline Male & $1996(55.80)$ & $397(54.16)$ & $316(55.73)$ & $488(56.09)$ & $549(57.43)$ & $246(54.55)$ \\
\hline Female & $1581(44.20)$ & $336(45.84)$ & $251(44.27)$ & $382(43.91)$ & $407(42.57)$ & $205(45.45)$ \\
\hline Race & 3395 & 695 & 536 & 837 & 910 & 417 \\
\hline White & $2686(79.12)$ & $524(75.40)$ & $413(77.05)$ & $669(79.93)$ & $750(82.42)$ & $330(79.14)$ \\
\hline Nonwhite & $709(20.88)$ & $171(24.60)$ & $123(22.95)$ & $168(20.07)$ & $160(17.58)$ & $87(20.86)$ \\
\hline Annual household income & 2129 & 467 & 356 & 530 & 526 & 250 \\
\hline$\geq \$ 100,000$ & $1245(58.48)$ & $265(56.75)$ & $233(65.45)$ & $304(57.36)$ & $301(57.22)$ & $142(56.80)$ \\
\hline$<\$ 100,000$ & $884(41.52)$ & $202(43.25)$ & $123(34.55)$ & $226(42.64)$ & $225(42.78)$ & $108(43.20)$ \\
\hline Household net worth & 3058 & 624 & 484 & 748 & 812 & 390 \\
\hline$\geq \$ 250,000$ & $1473(48.17)$ & $233(37.34)$ & $256(52.89)$ & $375(50.13)$ & $421(51.85)$ & $188(48.21)$ \\
\hline$<250,000$ & $1585(51.83)$ & $391(62.66)$ & $228(47.11)$ & $373(49.87)$ & $391(48.15)$ & $202(51.79)$ \\
\hline
\end{tabular}

Ages in years.

decompression were stratified into the same age brackets. Incidence rates per 1000 patients were calculated for each age bracket by dividing the number of surgical patients by enrollee coverage years in that age bracket, multiplied by the 4-year range of each bracket. This number was represented as surgical incidence per 1000 patients in each bracket. The cumulative incidence rate of requiring surgical intervention was calculated by summing the individual incidence rates for each age strata. Patients were also stratified by birth year into those in the first half of the study (2001-2007) versus those in the latter half (2008-2014), with comparisons made between each time period.

\section{Calculation of Length of Stay Following Surgical Decompression}

The inpatient stay corresponding to the surgical decompression was identified for each surgical patient. Length of stay was calculated by subtracting the discharge date from the admission date for that inpatient stay, with median and interquartile range calculated for aggregate data.

\section{Data Analysis and Statistics}

All data were examined and analyzed using SAS statistical software (version 9.4, SAS Institute Inc.). Results were compiled in Excel (Microsoft Corp.). Significance of group proportions was determined using chi-square tests of significance at the alpha $=0.05$ level .

\section{Results}

\section{Population Prevalence of Achondroplasia}

The prevalence of achondroplasia in the database population was 1.43 cases per 10,000 covered lives $(n=$ 8345 cases in a total of $58,800,802$ enrollees). This is in line with previous studies that demonstrated a population prevalence of achondroplasia from 0.36 to 1.5 cases per 10,000 people in the population. ${ }^{17,29}$

\section{Demographic Characteristics of Base Cohort}

Basic demographic characteristics for the overall base cohort of pediatric enrollees with achondroplasia $(n=$ 3577) are displayed in Table 1. Among the base cohort, $55.8 \%$ were male, $79.1 \%$ were white, $58.5 \%$ had an annual household income above $\$ 100,000$, and $48.2 \%$ had a household net worth of greater than $\$ 250,000$. Among the entire cohort, the average coverage length was $4.6 \pm$ 3.2 years.

\section{Screening Analysis}

There were 236 enrollees from the base cohort who were age 0 at the time of enrollment and had at least 18 months of continuous coverage. The average coverage length within the screening analysis cohort was $4.9 \pm 3.0$ years. Table 2 demonstrates the demographic characteristics of the unscreened versus screened enrollees. They are largely similar to the demographic distribution of the overall base cohort. There was no significant difference between the screened and unscreened cohorts with respect to sex distribution $(\mathrm{p}=0.16)$, race $(\mathrm{p}=0.23)$, and annual household income $(p=0.20)$. Regarding household net worth, the group that was screened had a significantly higher proportion of enrollees with a household net worth of less than $\$ 250,000(n=132)$ than did the unscreened group $(\mathrm{n}=75 ; \mathrm{p}=0.028)$.

Overall, $41.9 \%$ of enrollees (99 of 236) had some form of screening for foramen magnum stenosis, with either neuroimaging or a sleep study. Only $13.9 \%$ of enrollees (33 of 236) received screening (neuroimaging + sleep study) that was in accordance with published, standardof-care guidelines.

In terms of screening modalities, of those who underwent neuroimaging, 45 (48.4\%) had a CT scan as their first method of neuroimaging, whereas $48(51.6 \%)$ had an MRI scan. In total, $39(39.4 \%)$ of those who underwent some form of screening had a sleep study.

When we examined screening performance by time period, only $32.9 \%$ of patients with achondroplasia born from 2001 to 2007 were screened, whereas $60.3 \%$ of those born from 2008 to 2014 were screened ( $<$ 0.0001). These periods were chosen because they were a midpoint cor- 
TABLE 2. Demographic characteristics of patients according to screening status

\begin{tabular}{|c|c|c|c|c|}
\hline \multirow[b]{2}{*}{ Variable } & \multicolumn{4}{|c|}{ Screening Cohort No. (\%) } \\
\hline & Total & Unscreened & Screened & $\mathrm{p}$ Value \\
\hline Sex & 236 & 137 & 99 & 0.16 \\
\hline Male & $120(50.85)$ & $75(54.74)$ & $45(45.45)$ & \\
\hline Female & $116(49.15)$ & $62(45.26)$ & $54(54.55)$ & \\
\hline Race & 225 & 129 & 96 & 0.23 \\
\hline White & $179(79.56)$ & $99(76.74)$ & $80(83.33)$ & \\
\hline Nonwhite & $46(20.44)$ & $30(23.26)$ & $16(16.67)$ & \\
\hline $\begin{array}{l}\text { Annual household } \\
\text { income }\end{array}$ & 166 & 98 & 68 & 0.20 \\
\hline$\geq \$ 100,000$ & $100(60.24)$ & $63(64.29)$ & $37(54.41)$ & \\
\hline$<\$ 100,000$ & $66(39.76)$ & $35(35.71)$ & $31(45.59)$ & \\
\hline $\begin{array}{l}\text { Household net } \\
\text { worth }\end{array}$ & 207 & 120 & 87 & 0.028 \\
\hline$\geq \$ 250,000$ & 75 (36.23) & $51(42.50)$ & $24(27.59)$ & \\
\hline$<\$ 250,000$ & $132(63.7)$ & $69(57.50)$ & $63(72.41)$ & \\
\hline \multicolumn{5}{|l|}{$\begin{array}{l}\text { Screening by yr of } \\
\text { birth }\end{array}$} \\
\hline $2001-2007$ & 158 & 106 & $52(32.91)$ & $<0.0001$ \\
\hline 2008-2014 & 78 & 31 & $47(60.26)$ & \\
\hline
\end{tabular}

responding to 2 years after issuance of the new screening recommendations from the AAP.

\section{Incidence Rates of Surgical Intervention and Length of Stay}

Among children with achondroplasia, 25 patients were identified with cervicomedullary decompression, all of whom had CPT code 61343. The median (IQR) age at the time of surgery was $0.81(0.28-3.44)$ years, with a mean age of $2.64 \pm 4.46$ years. The average coverage length for enrollees who had surgery was $3.0 \pm 2.6$ years. Data on the incidence rates of surgical intervention are displayed in Table 3 and Fig. 2. The incidence rate of surgery varied by age: patients $0-3,4-7,8-11,12-15$, and $16-19$ years old underwent $27.54,1.35,0.91,0.95$, and 2.27 surgeries per 1000 patient-years, respectively. In total, the cumulative incidence of surgical decompression from ages 0 to 19 years was 33.02 surgeries per 1000 patient-years. The median length of stay after surgical decompression was similar across age brackets.

\section{Discussion}

From a large sample of 58.8 million enrollees receiving coverage in a private insurance network, using ICD9-CM diagnosis and CPT codes, we were able to identify a cohort of 3577 pediatric enrollees with achondroplasia. Using a subset of patients with continuous coverage from birth, we evaluated adherence to national standards for screening, and using the larger cohort, we determined the incidence of surgical decompression.

Of note, the overall cohort of pediatric enrollees with achondroplasia is skewed toward those of high socioeconomic status and those who are Caucasian. This likely
TABLE 3. Incidence rate of cervicomedullary decompression in children with achondroplasia

\begin{tabular}{ccccc}
\hline $\begin{array}{c}\text { Age } \\
(\mathrm{yrs})\end{array}$ & $\begin{array}{c}\text { No. of } \\
\text { Patients } \\
(\mathrm{N})\end{array}$ & $\begin{array}{c}\text { Total Coverage } \\
\text { in Patient-Yrs } \\
(\mathrm{N} \times \mathrm{C})\end{array}$ & $\begin{array}{c}\text { No. of } \\
\text { Ops } \\
(\mathrm{S})\end{array}$ & $\begin{array}{c}\text { Incidence Rate }(\mathrm{S} /(\mathrm{N} \times \mathrm{C})) \\
\text { Over 4-Yr Age Bracket per } \\
1000 \text { Patient-Yrs }\end{array}$ \\
\hline $0-3$ & 733 & 3049.83 & 21 & 27.54 \\
\hline $4-7$ & 567 & 2972.88 & 1 & 1.35 \\
\hline $8-11$ & 870 & 4397.46 & 1 & 0.91 \\
\hline $12-15$ & 956 & 4196.83 & 1 & 0.95 \\
\hline $16-19$ & 451 & 1761.17 & 1 & 2.27 \\
\hline
\end{tabular}

$\mathrm{C}=$ coverage $\mathrm{S}=$ surgery.

represents the nature of the data: claims from a privately insured healthcare network in the United States. Since private insurance coverage tends to be employer sponsored, individuals in this network are more likely to be economically advantaged.

\section{Screening Analysis}

In 2005, the AAP released an update to its recommendation for screening for foramen magnum stenosis in children with achondroplasia. ${ }^{27}$ The guidelines indicate that by approximately age 1 year, these children should undergo a neuroimaging study with either CT or MRI along with polysomnography to investigate central sleep apnea. In this analysis, we therefore restricted our cohort to patients who had coverage since age 0 and had at least 18 months of continuous coverage, in hopes of capturing the true screening rate. To the best of our knowledge, no previous studies have examined the rate of screening adherence in this population.

This analysis demonstrated that only $13.9 \%$ of children with achondroplasia received full screening in accordance with AAP guidelines. Only $41.9 \%$ received any type of screening, either with neuroimaging or with polysomnography. It is possible that this low rate of screening is due to the fact that achondroplasia is a relatively rare disease entity and that primary care pediatricians may be less familiar with all of the screening regimens these children are recommended to receive. Encouragingly, when examin-

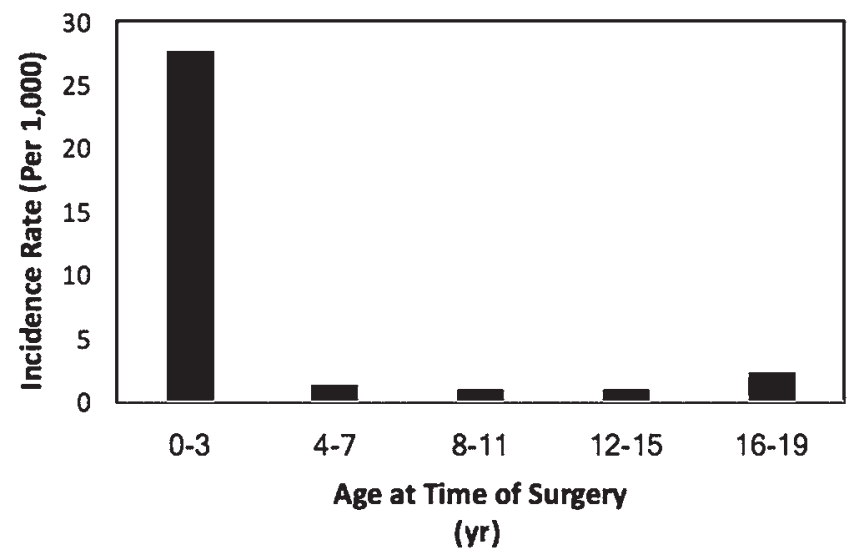

FIG. 2. Incidence of rate of surgery varies significantly by age, with the rate being highest in infancy. 
ing temporal trends of screening, the issuance of the 2005 recommendations did appear to increase the proportion of children who were screened: only $32.9 \%$ of those born from 2001 to 2007 were screened, whereas $60.3 \%$ of those born from 2008 to 2014 were screened. This substantial increase supports the continued expansion of practice guidelines for screening and surveillance of neurosurgical diseases. Given that the most recent revision of the AAP guideline for screening for foramen magnum stenosis is now more than 15 years old, again revising this guideline, incorporating new data about the rate of foramen magnum stenosis as well as known risks of general anesthesia and/ or radiation for screening, and widely publicizing its revision may lead to an even further increase in screening rates in future years.

Our calculated screening rates may be lower than the true rates due to shortcomings in identifying screening by administrative data. Patients mistakenly coded as having achondroplasia when in fact they do not would artificially depress the calculated screening rate. Possible explanations for a true low screening rate include unawareness of providers of the AAP guidelines and possible reluctance to undergo MRI or CT with their associated risks, however small. Additionally, off-recommendation screening techniques, including skeletal radiography, may have been performed in some cases but were not included in this analysis.

It is certainly important to understand whether CT irradiation or sedation for MRI for infants offers significant value and benefit. Importantly, this analysis does not enable definitive determination of the utility or cost-effectiveness of screening for foramen magnum stenosis. However, the low rate of surgery after infancy (presumably due to symptoms) relative to the rate of surgery in infancy (presumably due to asymptomatic screening) despite only half of patients being screened calls into question the utility of universal screening.

\section{Incidence of Cervicomedullary Decompression}

A number of single-center case reports have been published and establish the indications, safety, and efficacy of cervicomedullary decompression for the treatment of foramen magnum stenosis in children with achondroplasia. ${ }^{2,3}$, 11,14,16,23-25,32,33 However, given the limitations of single-center case series analyses, it remained unknown how many children with achondroplasia would undergo surgery.

We found that in a cohort of privately insured pediatric patients with achondroplasia, the cumulative incidence rate of surgery in childhood was 33 per 1000 patient-years. The incidence rate of surgery was 28 per 1000 patientyears for infants and 5 per 1000 patient-years for all other ages combined. It is likely that surgeries in infancy were the result of screening and those at later ages were because of symptoms.

This is the first study to estimate the cumulative incidence rate of foramen magnum decompression in patients with achondroplasia, providing a starting point for evaluating its necessity and effectiveness. Radiographic criteria for what constitutes foramen magnum stenosis are somewhat subjective, and given the relative rarity of achondroplasia, high-level evidence is lacking. Given that central apnea and sudden infant death are potential complications of brainstem compression, further studies may attempt to examine neurological outcomes from these surgeries, as well as delineate more specific criteria for the degree of stenosis that warrants decompression.

\section{Limitations}

The limitations of studies using claims data have been described previously. ${ }^{15}$ Specific to this analysis, the use of ICD codes to identify achondroplasia has not been validated previously, although the specificity of the code lends validity to accepting it at face value. Mistaken or "rule out" diagnosis codes may result in misclassifications of patients who do not in fact have achondroplasia, and these effects would cause underestimation of the true rates of screening and surgery as they would artificially increase the denominator. The unavailability of exact date of birth in the data set and the resulting approximation also introduces uncertainty in the calculation of age at surgery, though in aggregate the average ages should be relatively unaffected by our approximations. Further studies that include multicenter or registry data may help validate our results in the future. Finally, the demographics in this data set are skewed toward the inclusion of Caucasian and affluent individuals. This is likely because the data are derived from a sample of privately insured individuals in the United States. It is therefore possible that these results may not be fully generalizable to broader cohorts, and the results should be interpreted accordingly.

\section{Conclusions}

Using a nationwide insurance claims database of 58.8 million enrollees, we analyzed adherence to published screening guidelines as well as the incidence of cervicomedullary decompression for foramen magnum stenosis in children with achondroplasia. Only $13.9 \%$ of children with achondroplasia received screening in accordance with published guidelines of CT or MRI and a sleep study, and $41.9 \%$ received some form of screening. The cumulative incidence rate of surgical decompression during childhood for foramen magnum stenosis was 33 per 1000 patient-years. The incidence of surgery was highest in infants (28 per 1000 patient-years) and decreased with age (5 per 1000 patient-years for all other ages combined).

\section{Acknowledgments}

This study was supported by a TL1 Training Grant (J.L.N.; 1-TL1TR-002242-01) and an NS-007222 grant (D.A.W.), both from the National Institutes of Health (NIH). The content is solely the responsibility of the authors and does not necessarily represent the official views of the NIH.

\section{References}

1. American Academy of Pediatrics Committee on Genetics: Health supervision for children with achondroplasia. Pediatrics 95:443-451, 1995

2. Aryanpur J, Hurko O, Francomano C, Wang H, Carson B: Craniocervical decompression for cervicomedullary compression in pediatric patients with achondroplasia. J Neurosurg 73:375-382, 1990 
3. Bagley CA, Pindrik JA, Bookland MJ, Camara-Quintana JQ, Carson BS: Cervicomedullary decompression for foramen magnum stenosis in achondroplasia. J Neurosurg 104 (3 Suppl):166-172, 2006

4. Brühl K, Stoeter P, Wietek B, Schwarz M, Humpl T, Schumacher R, et al: Cerebral spinal fluid flow, venous drainage and spinal cord compression in achondroplastic children: impact of magnetic resonance findings for decompressive surgery at the cranio-cervical junction. Eur J Pediatr 160:10-20, 2001

5. Cohen ME, Rosenthal AD, Matson DD: Neurological abnormalities in achondroplastic children. J Pediatr 71:367-376, 1967

6. Dennis JP, Rosenberg HS, Alvord EC Jr: Megalencephaly, internal hydrocephalus and other neurological aspects of achondroplasia. Brain 84:427-445, 1961

7. Ednick M, Tinkle BT, Phromchairak J, Egelhoff J, Amin R, Simakajornboon N: Sleep-related respiratory abnormalities and arousal pattern in achondroplasia during early infancy. $\mathbf{J}$ Pediatr 155:510-515, 2009

8. Epstein JA, Malis LI: Compression of spinal cord and cauda equina in achondroplastic dwarfs. Neurology 5:875-881, 1955

9. Galanski M, Herrmann R, Knoche U: Neurological complications and myelographic features of achondroplasia. Neuroradiology 17:59-63, 1978

10. Hecht JT, Bodensteiner JB, Butler IJ: Neurologic manifestations of achondroplasia. Handb Clin Neurol 119:551-563, 2014

11. Hecht JT, Butler IJ, Horton WA: Foramen magnum decompression for homozygous achondroplasia. J Neurosurg 71:300-301, 1989

12. Hecht JT, Butler IJ, Scott CI Jr: Long-term neurological sequelae in achondroplasia. Eur J Pediatr 143:58-60, 1984

13. Jha RM, Klimo P, Smith ER: Foramen magnum stenosis from overgrow th of the opisthion in a child with achondroplasia. J Neurosurg Pediatr 2:136-138, 2008

14. Keiper GL Jr, Koch B, Crone KR: Achondroplasia and cervicomedullary compression: prospective evaluation and surgical treatment. Pediatr Neurosurg 31:78-83, 1999

15. Kestle JRW: Editorial. Administrative database research. J Neurosurg 122:441-442, 2015

16. Moskowitz N, Carson B, Kopits S, Levitt R, Hart G: Foramen magnum decompression in an infant with homozygous achondroplasia. Case report. J Neurosurg 70:126-128, 1989

17. Orioli IM, Castilla EE, Barbosa-Neto JG: The birth prevalence rates for the skeletal dysplasias. J Med Genet 23:328332, 1986

18. Pauli RM, Horton VK, Glinski LP, Reiser CA: Prospective assessment of risks for cervicomedullary-junction compression in infants with achondroplasia. Am J Hum Genet 56:732-744, 1995

19. Pauli RM, Scott CI, Wassman ER Jr, Gilbert EF, Leavitt LA, Ver Hoeve J, et al: Apnea and sudden unexpected death in infants with achondroplasia. J Pediatr 104:342-348, 1984

20. Reid CS, Pyeritz RE, Kopits SE, Maria BL, Wang H, McPherson RW, et al: Cervicomedullary compression in young patients with achondroplasia: value of comprehensive neurologic and respiratory evaluation. J Pediatr 110:522530,1987

21. Rollins N, Booth T, Shapiro K: The use of gated cine phase contrast and MR venography in achondroplasia. Childs Nerv Syst 16:569-577, 2000

22. Ruiz-Garcia M, Tovar-Baudin A, Del Castillo-Ruiz V, Rodriguez HP, Collado MA, Mora TM, et al: Early detection of neurological manifestations in achondroplasia. Childs Nerv Syst 13:208-213, 1997

23. Ryken TC, Menezes AH: Cervicomedullary compression in achondroplasia. J Neurosurg 81:43-48, 1994
24. Scott RM: Foramen magnum decompression in infants with homozygous achondroplasia. J Neurosurg 72:519, 1990

25. Shimony N, Ben-Sira L, Sivan Y, Constantini S, Roth J: Surgical treatment for cervicomedullary compression among infants with achondroplasia. Childs Nerv Syst 31:743-750, 2015

26. Simmons K, Hashmi SS, Scheuerle A, Canfield M, Hecht JT: Mortality in babies with achondroplasia: revisited. Birth Defects Res A Clin Mol Teratol 100:247-249, 2014

27. Trotter TL, Hall JG: Health supervision for children with achondroplasia. Pediatrics 116:771-783, 2005

28. Unger S, Bonafé L, Gouze E: Current care and investigational therapies in achondroplasia. Curr Osteoporos Rep 15:53-60, 2017

29. Waller DK, Correa A, Vo TM, Wang Y, Hobbs C, Langlois $\mathrm{PH}$, et al: The population-based prevalence of achondroplasia and thanatophoric dysplasia in selected regions of the US. Am J Med Genet A 146A:2385-2389, 2008

30. White KK, Parnell SE, Kifle Y, Blackledge M, Bompadre V: Is there a correlation between sleep disordered breathing and foramen magnum stenosis in children with achondroplasia? Am J Med Genet A 170A:32-41, 2016

31. Yamada H, Nakamura S, Tajima M, Kageyama N: Neurological manifestations of pediatric achondroplasia. J Neurosurg 54:49-57, 1981

32. Yamada Y, Ito H, Otsubo Y, Sekido K: Surgical management of cervicomedullary compression in achondroplasia. Childs Nerv Syst 12:737-741, 1996

33. Yundt KD, Park TS, Tantuwaya VS, Kaufman BA: Posterior fossa decompression without duraplasty in infants and young children for treatment of Chiari malformation and achondroplasia. Pediatr Neurosurg 25:221-226, 1996

\section{Disclosures}

The authors report no conflict of interest concerning the materials or methods used in this study or the findings specified in this paper.

\section{Author Contributions}

Conception and design: Maher, Nadel, Wilkinson. Acquisition of data: Maher, Nadel, Wilkinson. Analysis and interpretation of data: all authors. Drafting the article: Maher, Nadel, Wilkinson. Critically revising the article: all authors. Reviewed submitted version of manuscript: all authors. Approved the final version of the manuscript on behalf of all authors: Maher. Administrative/ technical/material support: Maher, Garton, Muraszko. Study supervision: Maher, Garton, Muraszko.

\section{Supplemental Information}

Online-Only Content

Supplemental material is available with the online version of the article.

Appendix Fig. 1. https://thejns.org/doi/suppl/10.3171/2018.9. PEDS18410.

\section{Previous Presentations}

An abstract based on this work was presented as an oral presentation at the 2018 AANS Annual Scientific Meeting, New Orleans, Louisiana, April 28-May 2, 2018.

\section{Correspondence}

Cormac O. Maher: University of Michigan, Ann Arbor, MI. cmaher@med.umich.edu. 